\title{
Collecting Traffic Video Data Using Portable Poles: Survey, Proposal, and Analysis
}

\author{
Morten B. Jensen ${ }^{1 *}$, Chris H. Bahnsen"1, Harry S. Lahrmann'2, Tanja K. O. Madsen², \\ Thomas B. Moeslund ${ }^{1}$ \\ ${ }^{1}$ Visual Analysis of People Laboratory, Aalborg University, Aalborg, Denmark \\ ${ }^{2}$ Traffic Research Group, Aalborg University, Aalborg, Denmark \\ Email: ‘mboj@crea te.a au.dk
}

How to cite this paper: Jensen, M.B. Bahnsen, C.H., Lahrmann, H.S., Madsen, T.K.O. and Moeslund, T.B. (2018) Collecting Traffic Video Data Using Portable Poles: Survey, Proposal, and Analysis. Journal of Transportation Technologies, $\mathbf{8}$, 376-400.

https://doi.org/10.4236/jtts.2018.84021

Received: October 9, 2018

Accepted: October 27, 2018

Published: October 30, 2018

Copyright $\odot 2018$ by authors and Scientific Research Publishing Inc. This work is licensed under the Creative Commons Attribution International License (CC BY 4.0).

http://creativecommons.org/licenses/by/4.0/

\section{(c) (i) Open Access}

\begin{abstract}
Several initiatives have been launched to help prevention of traffic accidents and near-accidents across the European Union. To aid the overall goal of reducing deaths and injuries related to traffic, one must understand the causation of the traffic accidents in order to prevent them. Rather than deploying a person to physically monitor a location, the task is eased by camera equipment installed in existing infrastructure, e.g. poles, and buildings, etc. In rural areas there is however a very limited infrastructure available which complicates the data acquisition. But even if there is infrastructure available in either the rural area or the urban area, this might not serve as an ideal position to capture video data from. In this work, we survey and provide an overview of available and relevant portable poles setups with respect to capturing data in both urban areas and rural areas. The conclusion of the survey shows a lack of a mobile, lightweight, compact, and easy deployable portable pole. We therefore design and develop a new portable pole meeting these requirements. The new proposed portable pole can be deployed by 2 persons in 2 hours in both rural areas as well as urban areas due to its compactness. The deployment and usage of the new portable pole is a complimentary tool, which may improve the camera capturing angle in case existing infrastructure is insufficient. This ultimately improves the traffic monitoring opportunities. Further, the survey of selected portable poles provides an excellent overview and can aid multiple applications within road traffic.
\end{abstract}

\section{Keywords}

Road Traffic, Video Analysis, Camera Mounting, Pole, Portable

\section{Introduction}

Preventing traffic accidents and near-accidents remains a major and interesting 
challenge to address for academic partners as well as public organizations. In 2017 alone, the European Union (EU) reported that 25,000 people lost their lives and 135,000 people were injured on the roads across the EU [1]. In 2009 the EU estimated that the deaths and injuries across Europe costed the society approximately 130 billion Euro [2]. As a result, the EU set out a 2010-2020 goal with an overall objective of halving road deaths across Europe. To achieve this, several initiatives have been started covering increased enforcement of road rules, improved education and training of road users, and safer road infrastructure, and promoted the use of modern technology to increase road safety (ITS), and protection of vulnerable road users (VRU). All of which are important to analysis and address to meet the overall objective in 2020 .

Understanding accidents causes in the traffic requires a lot of data, which can be collected with different purposes. Naturalistic Driving Study (NDS) such as the "100-Car Naturalistic Driving Study" [3] and the "SHRP2 Naturalistic Driving Study" [4], collects all sorts of data from within the participating vehicles such as GPS, accelerometer and similar vehicle network data, but the vehicles are also equipped with multiple different sensors, e.g. RGB cameras, thermal cameras, stereo cameras [5] or radars. Though these studies generate a lot of interesting data, a major drawback of this approach is the large investments needed to reach a large participant pool and then afterwards installing expensive equipment inside the car whilst keeping the car naturalistic.

A less expensive approach of capturing data that helps understanding accidents causes is simply to monitor and observe a critical location, e.g. traffic intersection. This manually task is however quite error-prone as the assigned person must be aware of everything happening in area of interest whilst continuously documenting the observations over a longer period of time. So rather than deploying a person to physically monitor a point of interest, the task is eased by mounting a camera-based system in existing infrastructure, e.g. poles, and buildings, etc. The captured video data can then be post-processed and analyzed with the purpose of understanding the scene and ultimately making adjustments that ideally prevents accidents and near-accidents. The main challenge of the camera-based system is that often there is no or very limited existing infrastructure available at the scene, thus directly impacting the quality of the analysis. This has spawned the use and interest in portable setups that can be moved around, which allows for a more optimal data collection in both urban areas but in particularly also in rural areas where there is often no proper infrastructure to mount cameras in.

In this paper, we make an analysis of relevant portable setups, where we discuss the pros and cons of different portable types and solutions, thorough overview of available setups. The result of the overview shows a lack of a mobile, lightweight, and easy deployable portable pole, thus we design and develop a new portable pole meeting these requirements.

The contributions of this paper are thus twofold: 
1) Providing a thorough analysis and overview of available portable camera-based capturing setups.

2) Design and development of a new mobile, lightweight, and easy deployable portable pole to ease camera-based data collection.

The paper is organized as follows: Section 2 describes the minimum requirements for the portable pole as well as the general definitions used. All of the requirements and definitions are then used examining various solutions ultimately providing an overview of available portable pole solutions in Section 3. In Section 4, the design and development of the new portable pole is presented. Usage and applications of new portable pole is presented in Section 5. In Section 6 we perform a discussion of our work. Finally, we present our conclusions in Section 7.

\section{Portable Pole Analysis}

Portable poles can serve multiple purposes and can be used for various applications. As briefly mentioned and introduced in Section 1, this survey will only consider portable pole solutions that could be relevant as a camera-based recording platform in the field of traffic surveillance and monitoring.

\subsection{Minimum Setup Requirements}

The relevant portable pole solutions are derived based on 4 minimum requirements that are considered essential for a portable pole to function as a proper camera-based recording platform, which can be utilized in both urban and rural traffic environments.

\subsubsection{Recording Time}

The video recordings are the basis for the entire analysis, so besides having a great view-angle provided by either the infrastructure or a portable pole, the video recordings must contain a sufficient amount of accidents or near-accidents in order to make some concluding remarks of a given location. In [6], the frequency of traffic accidents is described as a pyramid, where the pyramid base contains normal traffic encounters that are non-critical and rather safe, but very frequent. The pyramid apex contains the fatal and very severe events, e.g. fatal injuries, these are however occurring more infrequent compared to accidents in the lower part of the pyramid. Previous studies from Scandinavia show that a particular site, the number of near-accidents tends to be as low as 1 - 2 per day. [7] [8] [9].

So in order to get video recordings containing some infrequent events, the portable pole and camera-based setup must robust and stable enough to record continuously throughout a longer period of time. In this analysis we consider a period of 3 weeks to be the minimum requirement.

\subsubsection{Capturing Height}

A major issue to take into account when installing camera equipment at a point of interest is occlusion. Occlusion is in this case defined as when two objects are 
overlapping each other from the view-angle of the camera equipment, which makes the objects completely or partly occluded. In Figure 1 an example of this is shown, where the red car is clearly not visible from the specific camera-view mounted in existing infrastructure.

To reach the most accurate conclusion in a traffic analysis, the data needs to be as accurate as possible, thus we want as little occlusion as possible in the data collection. There are multiple ways of reducing occlusion, e.g. having multiple cameras from different view-angles or simply just by increasing the capturing height similar to Figure 1(b). In this analysis, we define a minimum capturing height of 7 meters for the portable pole, which is 3 meters higher than the maximum height limit for vehicles in most countries in Europe [10] [11].

\subsubsection{Ground Area Occupation}

To make sure, that the data collection is done in an as naturalistic and unobtrusive environment as possible, we need to make sure that the base does not cause any major impact on the behavior of the drivers on the road or the pedestrians on the sidewalk. Naturally, placing a new "intruder" in an existing environment may attract some attention and thus result in changed driver behavior, but the point of this demand is to keep it at a minimum by defining the maximum ground area occupation of the portable base to be 1.5 meters in the width. This should enable deployment of the portable pole in rural areas and in most urban environments as it can be deployed on the sidewalk whilst pedestrian should be able to easily walk around it. The maximum ground area occupation is only defined for the width, as this is the strictest one in terms of occupying the sidewalk. The length is less critical as people are still able to use the sidewalk, however it should preferably be under 2.5 meters.

\subsubsection{Payload Weight}

The portable pole setup must be able to handle the payload weight from the capturing devices mounted in the top. In this analysis, we suggest using both a RGB camera and thermal camera as capturing devices. Using multi-modal visual cues provides a solid data foundation for a later accident causation analysis as accidents and near-accidents do not solely happen in daylight [12]. Doing periods with a limited amount of light and challenging weather conditions, e.g. night, winter, rain. Thermal cameras are quite useful as illustrated in Figure 2, where both modalities are seen showing the same scene. The RGB camera is having a hard time coping with the headlights from the car and the low-light in the reminder of the scene. Furthermore, the RGB camera seen in Figure 2(a) is challenged by the weather conditions, i.e. rain. The thermal camera on the other hand do not rely on light to produce its output but infrared radiation, which clearly produce a more accessible output as seen in Figure 2(b), where the car is clearly visible.

The pole must therefore be able to handle a setup with two capturing devices. The capturing devices in this analysis are seen in Table 1, which defines a minimum payload weight requirement of $5.7 \mathrm{~kg}$. 


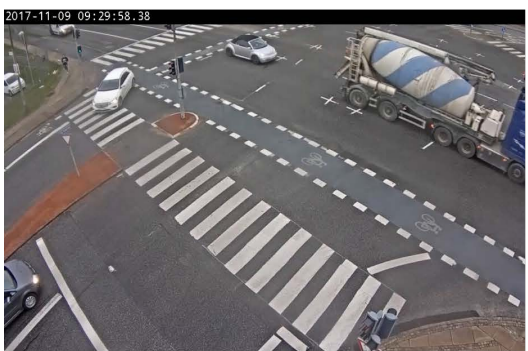

(a)

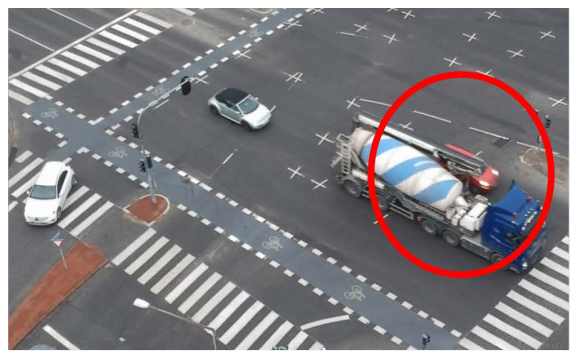

(b)

Figure 1. Objects can overlap each other in the camera-view as seen in (a) where the the large concrete truck clearly occludes the lane behind it. (b) Clearly shows that a red car is in fact driving side-by-side of the concrete truck.

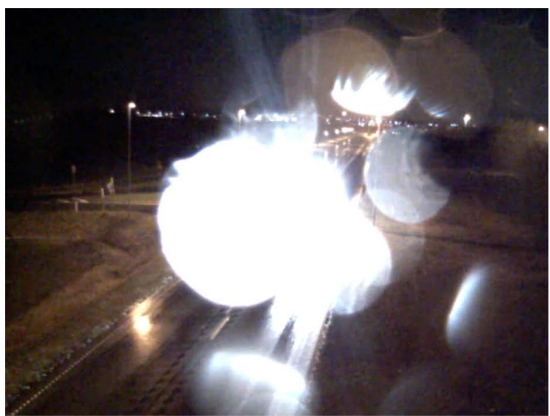

(a)

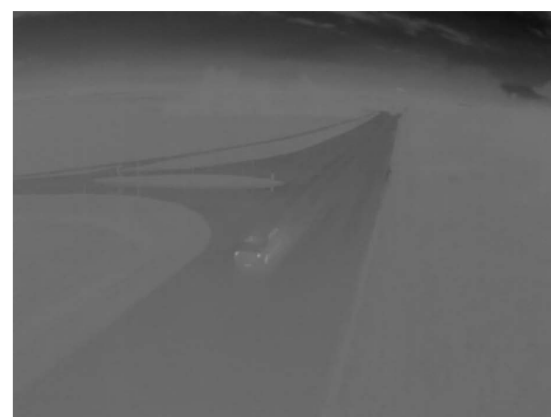

(b)

Figure 2. Data collection at 02:00 in the night using two modalities: (a) RGB camera (b) Thermal camera.

Table 1. Derivation of the minimum payload weight requirement using AXIS RGB camera and thermal camera.

\begin{tabular}{cccc}
\hline Type & Manufacturer & Model & Weight \\
\hline RGB & Axis & Q1615-E & $3.5 \mathrm{~kg}$ \\
Thermal & Axis & Q1932-E & $2.2 \mathrm{~kg}$ \\
& & & $5.7 \mathrm{~kg}$ \\
\hline
\end{tabular}

Below are the requirements for a portable pole listed, if nothing else is stated, these are minimum requirements.

1) Solution must be able to record continuously in 3 weeks.

2) Capturing height: $7 \mathrm{~m}$.

3) Maximum ground area occupation (Width): 1.5 meters.

4) Payload weight: $5.7 \mathrm{~kg}$.

\subsection{Portable Pole Types}

In this analysis, we have divided portable poles into 4 different types, which will also form the structure for the reminder of the portable pole analysis and overview, namely: 1) lightweight and compact portable pole with low payload; 2) compact portable pole with high payload; 3 ) trailer portable pole with high payload; and 4) heavyweight portable pole with high payload. 
The payload is the capacity which the portable pole is able to lift in the top during operation. The stability in the top of the pole, hence the recording usage quality, is dependent on the payload. Common for all of the portable pole types are that they all must comply with the minimum requirements defined in Section 2.1.

Type-1 Lightweight and compact portable pole with low payload: The main goal of this type is that they are very easily moved and transported between locations. The efforts needed for setting up this type of portable pole is very low. The setup and transportation of this type of portable pole is a one-person job, requiring it to be lightweight and compact. The stability and payload scales accordingly, resulting in a low payload to keep the pole stable in the top.

Type-2 Compact portable pole with high payload: Rather than being able to transport the portable pole by yourselves, this type consider more heavyweight equipped that can be assembled on-location by one or two persons. The equipment will remain compact while dissembled such it can be easily transported from location to location by use of a van or pick-up truck. When assembled the equipment is more robust compared to Type-1, but at the cost of easy mobility.

Type-3 Trailer portable pole with high payload: This type utilizes a trailer or small wagon which can be attached to a vehicle's hitch ball. All the equipment is installed upon this trailer, such that one or two persons can drive to a location and set up the portable pole without too much assembling and more lenient requirements for the level of the ground base. This provides a rather stable portable pole with some degree of mobility.

Type-4 Heavyweight portable pole with high payload: By using a large platform of e.g. concrete, all the equipment can be installed on this providing a robust platform for the portable pole. However, this require a large truck with a crane for transportation, but provides a good pre-assembled portable pole.

This division will form the structure for the portable pole overview section when surveying the corresponding available portable poles.

\section{Overview of Relevant Portable Poles}

The overview is divided into 6 parts. The first part introduces a general base framework that complies with the battery and storage requirements and is applicable for most of the portable poles presented. This is followed by 4 parts, one for each of the 4 portable pole types presented in Section 2.2. The final part presents an overview that summarizes all of the presented portable poles.

\subsection{Base Framework}

Regardless of the portable pole choice, the data recording capacity, the power supply and underlying video acquisition framework must fulfill the minimum requirements. Using aforementioned minimum requirements, we will in this subsection define a common framework that can be used together with the portable poles. 


\subsubsection{Video Acquisition}

The Axis cameras defined in Table 1 are capable of operating by Power over Ethernet (PoE) which means it is only necessary to supply one cable per camera in the mast. The cameras are by the use of a network switch connected to a Synology DS215j Network Allocated Storage (NAS) server, where the acquired video data must be properly stored. The storage capacity required is heuristically derived to be no less than 6 TB in order to keep 3-weeks of data using H.264 compression.

\subsubsection{Power Supply and Enclosure}

The video acquisition hardware presented above must be powered throughout the 3-week acquisition period. The power supply and some of the video acquisition hardware must also be placed in an enclosure which is resistant to tampering.

The video acquisition hardware consumes approximately 30 watts in operation, which make a self-contained setup unfeasible due to 3-weeks video acquisition requirement. Instead we use 3 heavy-duty 12 volt 180 Ah batteries, which provides the setup with an approximately replacement cycle of $4-6$ days depending on the overhead and wear out of the batteries.

The entire system is finally installed in an IP65-certified Eurobox 40705, which can be seen in Figure 3.

\subsection{Type-1: Lightweight and Compact Portable Pole with Low Payload}

The first type of poles, is as introduced in Section 2.2, the most compact and lightweight ones, and should ideally be deployable for a single person.

\subsubsection{Miovision Scout}

Scout is a portable and expanded pole developed by Miovision, and is, according to their own documentation, "designed specifically with the users in mind" [13]. This has resulted in a portable pole with a weight of only $19.1 \mathrm{~kg}$ and a set up time of 10 minutes. The Miovision Scout do not meet the requirements for this analysis, defined in Section 2.1 as it is not configurable for the two cameras defined in Table 1. It is however still included as it is a very popular solution for traffic monitoring, and might be usable in pilot tests or as a second view-angle.

The Miovision Scout has a battery life of 7 days when buying the additional power pack and can be set up on existing infrastructure using an included pole mount. The simplicity of the product can easily be deducted by examining Figure 4. In case deployment is needed in places without street poles, a separately sold Scout Tripod can be used. The Scout Tripod weights $14 \mathrm{~kg}$, but can reach 68 $\mathrm{kg}$ with additional security weights. The Miovision Scout is equipped with a wide lux camera with $120^{\circ}$ horizontal view capturing with a resolution of $720 \times$ 480 pixels @ 30 FPS. As mentioned in the introduction, this camera setup is not configurable. The operational height can be adjusted to be between 1.32 - 6.4 


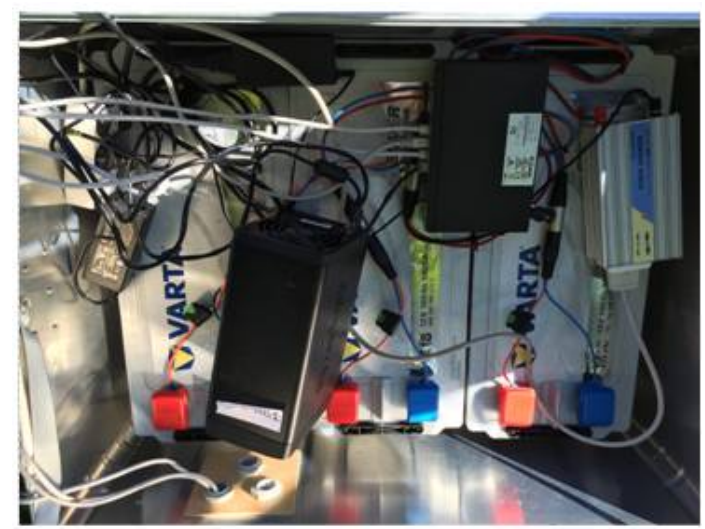

Figure 3. The Eurobox 40705 containing 3 batteries, a $230 \mathrm{~V}$ power inverter, a PoE switch, and a NAS server.
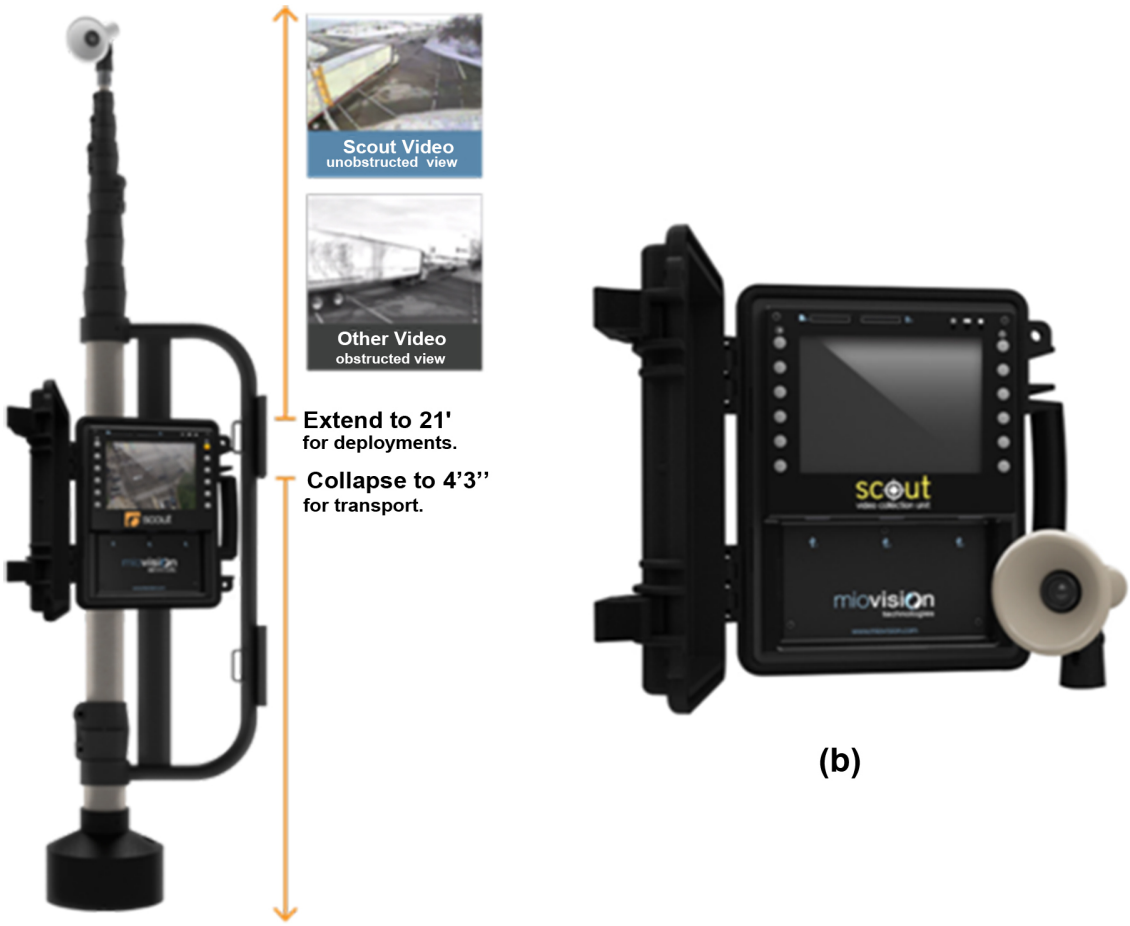

(b)

(a)

Figure 4. The lightweight and compact, but non-configurable, portable pole from Miovision. (a) Miovision Scout with the extendable pole [12] (b) Miovision Scout video collection unit [12].

meters, which do not meet the requirements either. In Table 2 an overview of the required equipment is summarized.

The Miovision Scout can be mounted to existing infrastructure, such as a pole, defining some requirements to how poles or similar objects are located at an intersection. Otherwise the Scout Tripod can be used to deploy the Scout. For both of the solutions no major equipment is needed, and one person should be able to set this up in an hour. 
Table 2. Required equipment for the miovison scout.

\begin{tabular}{cc}
\hline Product & Weight \\
\hline Scout video collection unit & $10.89 \mathrm{~kg}$ \\
Scout pole mount & $8.16 \mathrm{~kg}$ \\
Scout power pack & $14.0 \mathrm{~kg}$ \\
Scout tripod & $14.0 \mathrm{~kg}$ \\
\hline
\end{tabular}

\subsubsection{Custom Lightweight Portable Pole}

This portable pole is a proposal on how a lightweight portable pole could be manufactured. The portable pole must meet the requirements defined in Section 2.1, while being a lightweight solution easily transported around.

The portable pole utilizes the Clark Masts SFT9-6 mast, which can be extended to 8.8 meters using a hand pump, and remains at 2.05 meters in retracted mode. An image of a FT series mast from Clark masts is seen in Figure 5(a). On top of this there must be created a rig which cameras can be mounted in. The mast comes with a carrying bag, seen in Figure 5(b) for easier transportation. In addition to the bag, equipment such as spikes and radius lines are also included. This solution must also utilize the base framework presented in Section 3.1. In addition to the base framework, Table 3 summarizes the additional required equipment to manufacture this type of pole.

A van must be used to transport the equipment from location to location as the mast is 2.05 meters long, but setting up the equipment should be doable for one person. Using the radius line to make a guying system is however not really feasible in urban places, requiring the wind speed to be low for the setup to remain usable.

\subsubsection{Discussion}

The Miovision Scout do not meet the configurable requirements defined in Section 2.1 and can therefore not be used in the final setup. It might, however, be a useful solution for some minor pilots tests or be used a second view-angle at a complex environment. The custom made portable pole is not as lightweight as the Miovision Scout as one needs to bring more equipment to meet the requirements of capturing data continuously in 3 weeks. The custom made portable pole can be configured to have 2 cameras installed, but it is however considered necessary to utilize a guying system in order to stabilize the portable pole sufficiently, even in low wind conditions, such the video recordings are stable and usable for a traffic analysis.

\subsection{Type-2: Compact Portable Pole with High Payload}

We divide possible solutions for systems using a compact portable pole with high payload into three proposals based on the estimated total weight of the system: lightweight, middleweight, and heavyweight. All of them utilize the base framework presented in Section 3.1. 


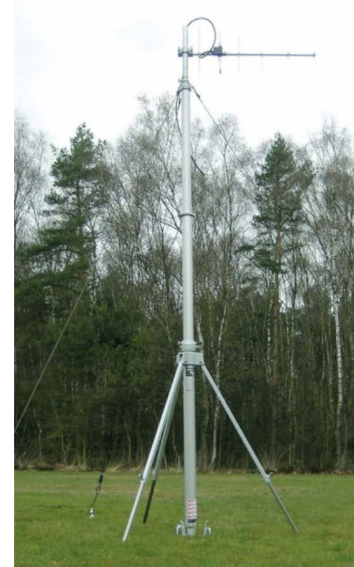

(a)

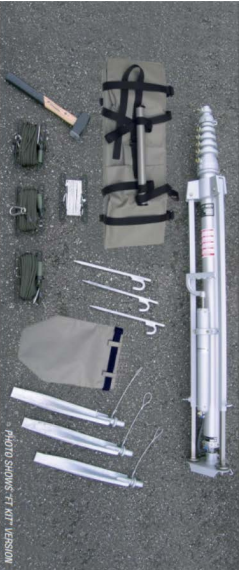

(b)

Figure 5. Parts for a custom lightweight portable pole (a) Clark Mast FT mast [19] (b) Clark Mast FT carrying bag [19].

Table 3. Equipment needed for custom lightweight portable pole. An unknown weight is marked with a “-”.

\begin{tabular}{clc}
\hline Product & \multicolumn{1}{c}{ Model } & Weight \\
\hline $\begin{array}{c}\text { Telescopic } \\
\text { mast }\end{array}$ & $\begin{array}{l}\text { Clark Masts FT series, SFT9-6/HP 10 kg headload, 8.80 m extended } \\
\text { height, 2.05 m retracted height, w. tripod }\end{array}$ & - \\
Carrying bag & Clark carrying bag, SFT9-6/HP Bag & - \\
\hline
\end{tabular}

\subsubsection{Lightweight: Mast with Tripod}

The lightweight portable solution consists of a telescopic, 5-section mast with a corresponding tripod. The extended mast is usually secured by a guying system to assure stability under heavy payload and wind speeds. However, as guying is not applicable in urban areas, we include a tripod to ensure stability. The tripod furthermore ensures independence of existing infrastructure and comes in a variety of sizes for different mast heights. An image of such a pole is seen in Figure 6.

We choose the largest mobile tripod available to provide stability and accommodate the requirements even under moderate wind speeds and payloads. The base diameter of the tripod is $2 \mathrm{~m}$, which have a recommend maximum mast height of $10 \mathrm{~m}$. When the mast is not guyed, the maximum wind speed is $13.8 \mathrm{~m} / \mathrm{s}$ for stable operation. A wind speed of $13.8 \mathrm{~m} / \mathrm{s}$ translates to "Strong Breeze" on the Beaufort scale.

The necessary equipments for the lightweight mast with tripod are listed in Table 4.

The transportation of the equipment requires a medium-to-large sized car or van to accommodate the length of the retracted mast and the total weight of the equipment. The telescopic mast is extended by an integrated hand pump, and the extended section is subsequently locked manually by using the provided screws. The ground area required for the base is $0.5 \mathrm{~m}$ larger than specified in 


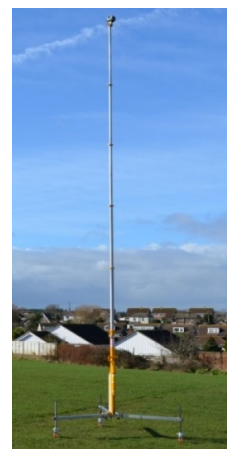

Figure 6. Clark QT Mast on tripod [20].

Table 4. Required equipment for compact, lightweight portable pole with high payload. Maximum wind speed $13.8 \mathrm{~m} / \mathrm{s}$. An unknown weight is marked with a “-”.

\begin{tabular}{clc}
\hline \multicolumn{1}{c}{ Product } & \multicolumn{1}{c}{ Model } & Weight \\
\hline Telescopic mast & $\begin{array}{l}\text { Clark QT Series, SQT9-5, } 5 \text { section mast 18 kg payload, } 9.00 \mathrm{~m} \\
\text { extended height, 2.25 m retracted height }\end{array}$ & - \\
Tripod & Clark MK VI, MK6 2000 MM & $18.0 \mathrm{~kg}$ \\
Tripod adapter & Clark & - \\
\hline
\end{tabular}

the setup requirements. The extra space is however necessary for the stability of the portable pole.

\subsubsection{Middleweight: Mast with Tripod}

The lightweight setup, described in Section 3.3.1, is used as a point of departure for the middleweight portable setup where the telescopic mast and tripod remain key components. The Clark QT mast from the lightweight setup is replaced by the heavier and sturdier NT series and features only 4 sections compared to the 5 section QT mast. The heavier mast calls for a heavier and larger tripod which is found in the Clark MK IV Tripod. The tripod weighs $27 \mathrm{~kg}$ and features a base diameter of $2.6 \mathrm{~m}$. As with the lightweight mast with tripod, the un-guyed mast is stable up to wind speeds of $13.8 \mathrm{~m} / \mathrm{s}$. The equipment of the middleweight mast with tripod is listed in Table 5.

Due to the larger retracted height of the telescopic mast $(2.82 \mathrm{~m})$ it might be impossible to fit inside an ordinary car, and thus a larger van is recommended. The telescopic mast is extended by the use of a hand pump and the sections are secured by screws similarly to the lightweight setup. The ground area required is even larger than for the lightweight scenario; however, this is needed in order to provide stability for the heavier mast.

\subsubsection{Heavyweight: Flyintower}

The heavyweight compact portable pole solution uses a Flyintower, or sound tower, as the camera mast. The Flyintower is a well-known object at large concerts or festivals where it is used for the lifting of loudspeakers as depicted in Figure 7. The V-shaped basement, the metal grid, and the heavy weight of the construction improve the sturdiness and stability of the setup. 
Table 5. Required equipment for compact, middleweight portable pole with high payload. Maximum wind speed $13.8 \mathrm{~m} / \mathrm{s}$. An unknown weight is marked with a "-".

\begin{tabular}{clc}
\hline \multicolumn{1}{c}{ Product } & \multicolumn{1}{c}{ Model } & Weight \\
\hline Telescopic mast & $\begin{array}{l}\text { Clark NT Series, NT 90-4, 4-section mast, 15 kg payload, } 9.00 \mathrm{~m} \\
\text { extended height, 2.82 m retracted height }\end{array}$ & $41.0 \mathrm{~kg}$ \\
Tripod & Clark MK IV & $27.0 \mathrm{~kg}$ \\
Tripod adapter & Clark & - \\
\hline
\end{tabular}

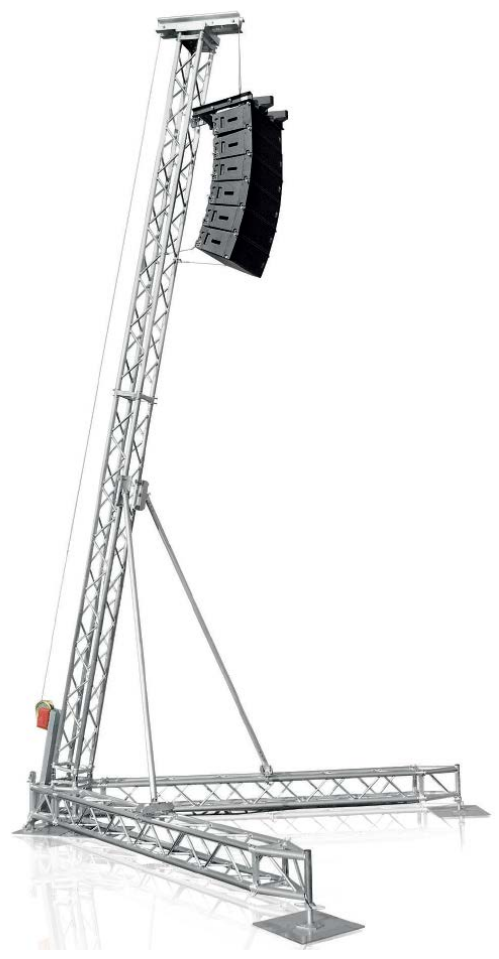

Figure 7. Litec 7.5-500 Flyintower [21].

We choose the smallest possible Flyintower from Litec to minimize the ground occupation area required for the basement of the tower. The extended height of the tower is $7.75 \mathrm{~m}$ and due to the $\mathrm{V}$-shaped basement, the footprint is $4.1 \times 3.6 \mathrm{~m}$. The maximum lifting load capacity of the tower is $500 \mathrm{~kg}$ which requires additional ballast at the base for stability. For the much lighter loads required in this setup, the required ballast weight is reduced. Due to the studier nature of the setup, the maximum wind speed is increased compared to the lightweight and middleweight setups. A list of the equipment is found in Table 6.

The Flyintower is considerably heavier than the mast-based solutions listed above. However, the tower might be taken apart and assembled on-site which greatly reduces the space needed for storage and transportation. We therefore estimate that a larger van is needed for the transportation, just as in the middleweight scenario. Compared to the lightweight and middleweight scenarios, the Flyintower requires a larger, planar surface for the base to stand. This might exclude the deployment in tight urban spaces where such space is not available. 
Table 6. Required equipment for compact, heavyweight portable pole with high payload. Maximum wind speed $70 \mathrm{~km} / \mathrm{h}$. An unknown weight is marked with a “-”.

\begin{tabular}{ccc}
\hline Product & Model & Weight \\
\hline Flyintower & Litec $7.5-500,500 \mathrm{~kg}$ max load capacity, $7.75 \mathrm{~m}$ extended height & $160.0 \mathrm{~kg}$ \\
Ballast & Required ballast & - \\
\hline
\end{tabular}

\subsubsection{Discussion}

For both the lightportable poles and middleweight portable poles, issues arise when dealing with higher wind speeds as the equipment is mounted in the top making the setup unstable. To cope with this, a guying system can be installed to stabilize the mast, this is however not feasible in urban places. For most scenarios in urban environments, both portable pole setups are considered usable in terms of wind speeds. The heavyweight solution is therefore a better overall option due to increased stability, but significantly comprising the compactness and weight compared to the lightweight and middleweight solutions.

Generally, all of the solutions can possibly be disassembled and be somehow compact and then be used in rural areas where there are more open space, it is however not ideal that none of the proposals meet the maximum ground occupation area requirement. Deploying any of the introduced solutions in this section in an urban environment will most likely be considered unnaturalistic and obtrusive.

\subsection{Type-3: Trailer Portable Pole with High Payload}

The third type of portable poles differs from the both type- 1 and type- 2 in the sense that the equipment used comes in a more wrapped up and easy-deployable way. As mentioned in Section 2.2, type-3 relies on equipment installed either in a trailer or in a small wagon resulting in less assembling on-site.

\subsubsection{UTRa Car}

The Urban Traffic Research CAR is developed for the national aeronautics and space research center of the Federal Republic of Germany (DLR) [14] and is equipped with a large set of sensors and systems to be used for traffic surveillance and data acquisition in the field. The car is seen in Figure 8(a) in transportation mode and in Figure 8(b) where the left image show an image of the car in operation [15]. The UTRaCar does not meet the requirement of the maximum ground occupation area, but is included as it provides some interesting solution ideas.

The car is equipped with multiple sensors as seen from the images in Figure 8(b). For this analysis, the telescopic mast seen in the left image is the most interesting one. A telescopic mast is mounted in the back of the car, and can extend to 13 meters. In the top of the telescopic mast various sensors can be installed, as seen in the upper right image in Figure 8(b). According to [14], the power supply unit in the car is self-sufficient. It is unclear what this covers, but from the lower image in Figure 8(b), it is clear that a lot of equipment can be 


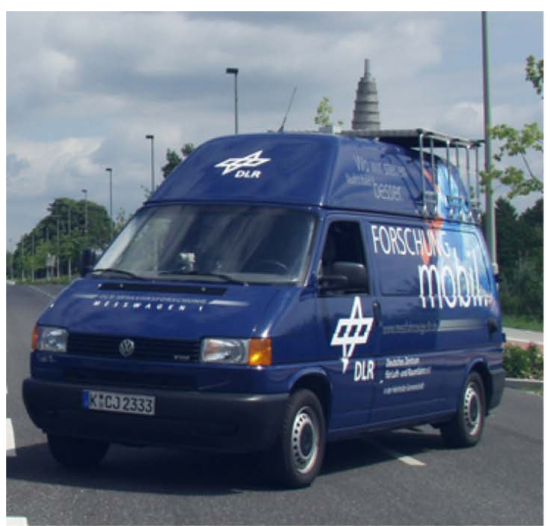

(a)

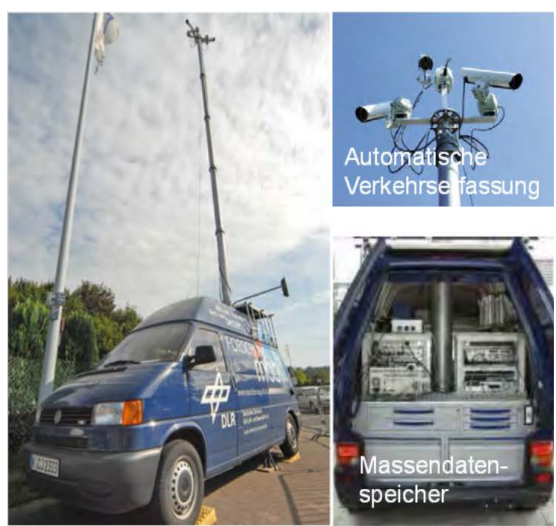

(b)

Figure 8. (a) The DLR UTRaCar with retracted telescopic mast. (b) The DLR UTRaCar with extracted telescopic mast [14].

installed in the of the car. In Table 7 an estimate of the equipment needed for a minimum requirement solution are seen.

The size of the car can be a challenge at a lot of intersections, so there must be some open areas around the intersection for deploying this system. But if the area suffices, a solution like this allows a rather fast deployment without any external actors.

\subsubsection{Trivector Mobile Mast}

The Swedish based company Trivector has developed the TMV1, which is a mobile mast installed in a trailer with the scope of capturing traffic situations, when extracted the height can reach up to 15 meters. In Figure 9(a) an image of the setup is shown, and in Figure 9(b) it is visible that the setup utilizes two cameras in operation meeting the requirements for this analysis.

The setup consists of a trailer equipped with a custom made telescopic mast. Inside the trailer all the equipment can be stored, and given from the image seen in Figure 9(a), it is clear that box is rather large, providing good possibilities to put all equipment inside. There exists no technical data sheet available to the public, hence it is hard to estimate the equipment used to create the Trivector mobile mast. From examining the figures the minimum requirements are a cargo trailer and a telescopic mast.

As for the UTRaCar, the setup occupies a rather large area on the ground, making it difficult to place in some urban areas. The installation complexity is low as it all equipment are inside the trailer, so the deployment is straightforward with a minimum of external actors. Finally, a car is needed to tow this setup from point $\mathrm{A}$ to point $\mathrm{B}$.

\subsubsection{Custom Made Trailer}

With inspiration of the previously solutions in type-3, we look into to assembling a trailer portable pole. The main idea is to utilize a trailer solution with a pole mounted on it. 
Table 7. Estimated equipment needed for a minimum requirement version of the UTRaCar. An unknown weight is marked with a “-”.

\begin{tabular}{clc}
\hline Product & \multicolumn{1}{c}{ Model } & Weight \\
\hline Van & VW Crafter 35 with medium wheelbase and high roof & - \\
Telescopic mast & $\begin{array}{l}\text { Clark WT Series, WT100-4, } 4 \text { Section mast, } 140 \mathrm{~kg} \text { headload, } 10.0 \mathrm{~m} \\
\text { extended height, 3.32 m retracted }\end{array}$ & - \\
\hline
\end{tabular}

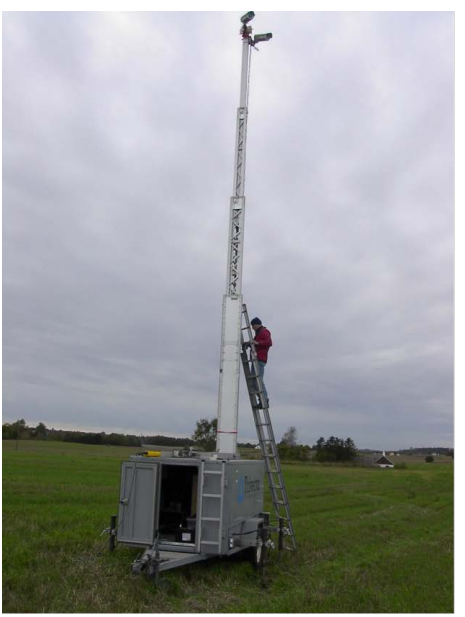

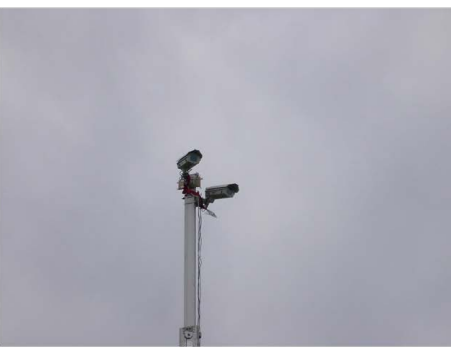

(b)

(a)

Figure 9. (a) The Trivector Mobile mast setup in operation. (b) The Trivector Mobile mast with two installed cameras. Images provided by Aliaksei Laureshyn, Lund University.

In Figure 10(a) and Figure 10(b) the main component in the setup is seen. It consists of an already existing product which needs to be customized to accommodate the minimum requirements.

Though there are some boxes and containers mounted in the original Clark Mast 804-15-6, additional room is considered necessitated to meet the capacity requirements. The 6 section XT Series mast mounted on the trailer has an extracted height of 15 meters [16].

A vehicle is needed to tow the trailer from location to location. A regular van is considered to be sufficient to tow the trailer and the remaining equipment. The length of the trailer is 6.3 meters, making it quite large and difficult to deploy in tight urban spaces.

\subsubsection{Discussion}

For all of the trailer solutions the main advantages are the easy and rather fast deployment as a very limited amount of external actors are needed. Other advantages of the type- 3 solutions are a "all-in-one" solution in the sense that room for batteries, HDD and other equipment is included in the setup. The disadvantages are that they can rather fast become quite expensive, and they do not scale very well in the sense of transportation from point A to point B might require multiple cars or a large truck. The weight and size of the solutions also occupies a large ground area which challenges one of the requirements defined for 


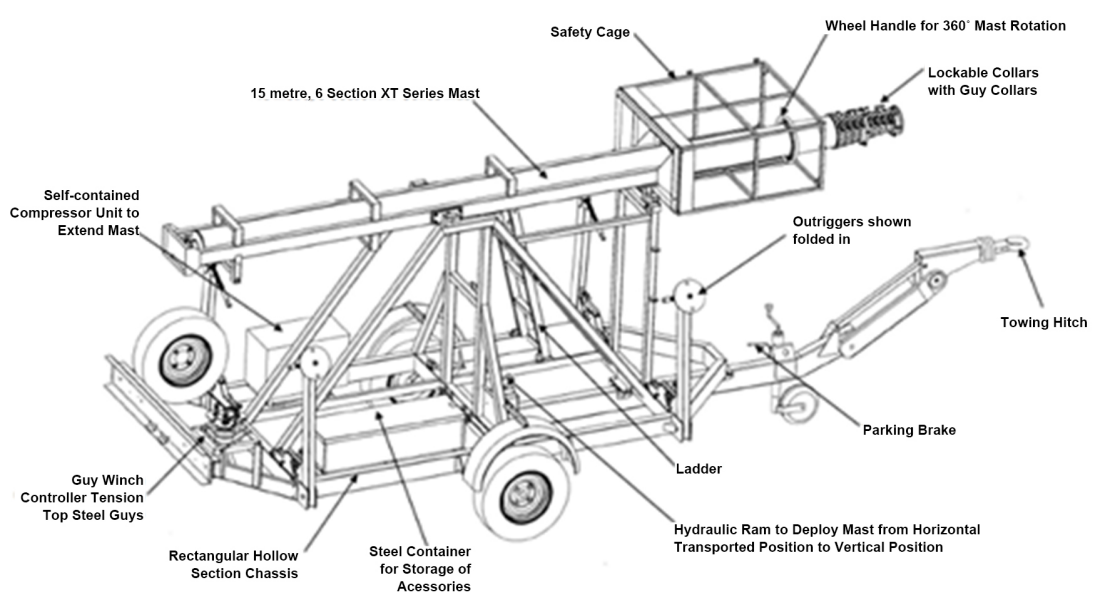

(a)
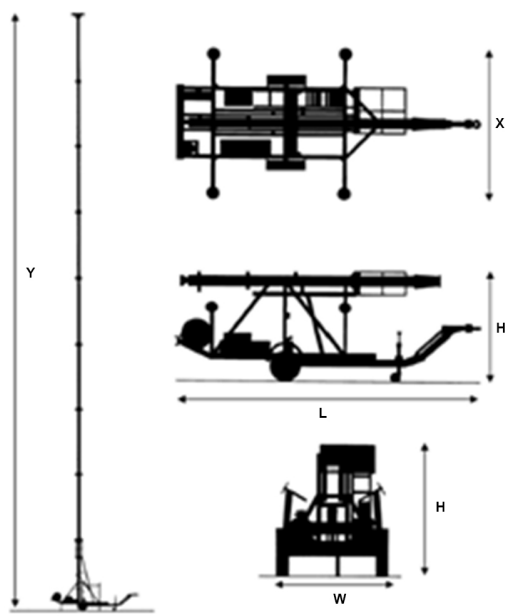

(b)

Figure 10. Specifications and overview of Clark Mast 804-15-6 [15].

this analysis. Furthermore, a regular driver's license might not be sufficient for all of the solutions.

The UTRaCar solution is considered to become quite expensive to build, so the best option in type- 3 is to use a solution similar to the Trivector mobile mast or the custom made trailer, even though it is also expected to become expensive.

\subsection{Type-4: Heavyweight Portable Pole with High Payload}

The last type of portable poles takes it starting point in a large platform of e.g. concrete, where all equipment can be installed upon. This complicates the transportation phase but should have advantages in operation compared to the previous types.

\subsubsection{DLR Platform}

The National Aeronautics and Space Research Centre of the Federal Republic of Germany (DLR) have used a portable platform for data capturing. The development of the technical aspects of the portable platform was carried out by Jenoptik. One of the usages of it has been to monitor railroads crossings as seen in Figure 11(a). The camera equipment used in the DLR portable pole setup consist of 4 cameras, 2 IR-flashes, 2 radars, and an aluminumframe, totaling a payload weight of $25.4 \mathrm{~kg}$. In operation mode, the camera fixed to an operational height of approximately 4 - 5 meters [17].

As seen from Figure 11 it is clear that the entire portable pole consists of a cabinet and a port that is split into two pieces, and is mounted onto a large concrete block. In operation mode, the pole is angled in vertical position, opposite to the horizontal transportation angle seen in Figure 11(b). The equipment needed for creating a portable pole for meeting the minimum requirements are seen in Table 8. The mast could however be changed to a telescopic mast.

According to an interview with Kay Gimm and SaschaKnake-Langhorst from DLR, it can require up to a whole day to setup and calibrate the sensors for the 


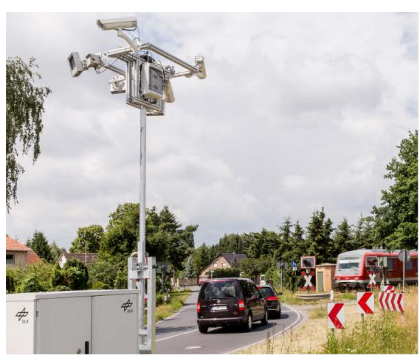

(a)

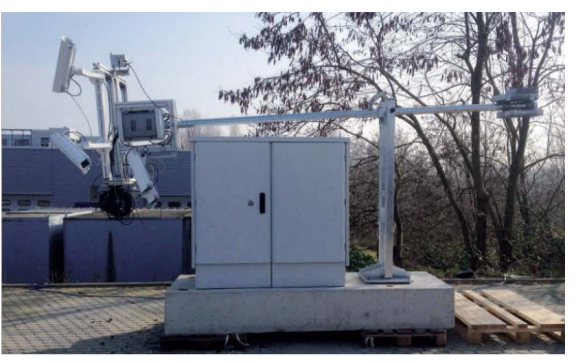

(b)

Figure 11. (a) DLR Setup in operation mode. (b) DLR Setup in transportation mode [16].

Table 8. Required equipment for heavyweight portable pole with high payload mounted on a concrete block. An unknown weight or model is marked with a "_".

\begin{tabular}{ccc}
\hline Product & Model & Weight \\
\hline Custom mast & Mast divided into two parts: Transportation and operation mode & - \\
Concrete platform & - & - \\
\hline
\end{tabular}

specific application, as the current system requires power supply access from the current infrastructure. Due to that concrete block, the setup is quite heavy requiring a truck and crane to move it around.

\subsubsection{Discussion}

Only one solution is presented for the type-4, which is the DLR setup. This setup provides a good and solid platform for data capturing. Installed on the concrete block is all the equipment needed making it a "all-in-one" solution. However, the setup is heavy meaning a truck and crane is needed for transportation and deployment.

\subsection{Overview}

Creating a setup that is lightweight, robust, and as mobile as possible is a hard problem to satisfy. It might become easier to record traffic data at certain intersections if using a small and lightweight setup. One can, however, not be certain of the quality of the recordings as lightweight usually correlates with instability during varying weather conditions; especially when considering that the setup has a relatively heavy camera rig mounted in the top. All of the surveyed options are seen in Table 9.

The main parameter to satisfy is considered to be the recording quality, as the quality of the data is essential for performing a good traffic analysis. Taking this into account, the proposed solutions from both type- 1 and type- 2 are not good options as they require guying systems in order to reach stability for prolonged periods of time. Guying systems are not ideal in urban environments, and the lightweight and compact pole solutions examined in this analysis does therefore not pose an ideal fit for the requirements. 
Table 9. Overview of the analyzed portable poles. The poles are summarized and can easily be compared on the 7 different parameters.

\begin{tabular}{|c|c|c|c|c|c|c|c|c|}
\hline Type & Type Name & $\begin{array}{l}\text { Operational } \\
\text { height }[\mathrm{m}]\end{array}$ & Payload [kg] & $\begin{array}{l}\text { Operational base } \\
\text { dimensions } \\
{[\mathrm{L} \times \mathrm{W} \times \mathrm{H}[\mathrm{m}]]}\end{array}$ & $\begin{array}{c}\text { Transport } \\
\text { dimensions } \\
{[\mathrm{L} \times \mathrm{W} \times \mathrm{H}[\mathrm{m}]]}\end{array}$ & $\begin{array}{l}\text { Weight } \\
{[\mathrm{KG}]}\end{array}$ & Configurable & $\begin{array}{c}\text { Deployment } \\
\text { equipment }\end{array}$ \\
\hline \multirow[b]{2}{*}{1} & Miovision scout & $1.3-6.4$ & - & $1.5 \times 1.5 \times 1.24$ & - & 48 & No & Car \\
\hline & $\begin{array}{l}\text { Custom lightweight } \\
\text { portable pole }\end{array}$ & 8.8 & 10 & - & $2.05 \times 0.25 \times 0.25$ & - & Yes & Van \\
\hline \multirow{3}{*}{2} & Lightweight: Mast with tripod & 9.0 & 18 & $2.0 \times 2.0 \times 9.0$ & $2.25 \times 0.4 \times 0.4$ & - & Yes & Car \\
\hline & $\begin{array}{l}\text { Middleweight: Mast } \\
\text { with tripod }\end{array}$ & 9.0 & 15 & $2.6 \times 2.6 \times 9.0$ & $2.8 \times 0.4 \times 0.4$ & 68 & Yes & Car \\
\hline & Heavyweight: Flyintower & 7.75 & 500 & $4.1 \times 3.6 \times 7.75$ & - & $>160$ & Yes & Van \\
\hline \multirow{3}{*}{3} & UTRaCAR & 13 & - & $5.9 \times 2.4 \times 13$ & $5.9 \times 2.4 \times 2.4$ & $>2800$ & Yes & - \\
\hline & Trivector Mobile mast & 15 & - & - & - & - & Yes & Car \\
\hline & Custom made trailer & 15 & 140 & $6.3 \times 1.95 \times 15$ & $6.3 \times 1.95 \times 2.2$ & - & Yes & Car \\
\hline 4 & DLR Platform & $4-5$ & 25.4 & - & - & - & Yes & Truck, Crane \\
\hline
\end{tabular}

For both type- 3 and type-4, the solutions presented will provide some more stable recording platforms however they are considered quite expensive to produce, and does therefore not scale very well. Furthermore, the solutions of type-3 are in most cases wider than the specified maximum of 1.5 meters, hampering the deployment on the sidewalk without interrupting the pedestrians. The type-3 solutions are, however, more mobile compared to the type- 4 solution, but in both cases a regular driver's license might not be sufficient. Additionally, the trailer option does not scale well as multiple trailers requires multiple towing vehicles.

This leads to the conclusion that for capturing the most stable and useful data, the setup must comprise the lightweight and easy mobility requirements. For type- 1 and type- 2 solutions to work, various guying system must be installed on existing infrastructure to fixate the pole. If one involves the existing infrastructure, a better result would be reached if the capturing rig is mounted on the infrastructure rather than using a lightweight or compact portable pole with guying installation. The type- 4 solution from DLR requires both a truck and a crane to deploy, which satisfies most of the requirements for this analysis, but remains, however, the less mobile solution in this analysis.

\section{Design \& Development of TRG-Pole}

In this section, we will present a pole which is hybrid between a type- 2 and type- 4 portable pole solution designed specifically to contain the same advantages as the DLR solution while being mobile.

\section{The Designed Pole}

We present a portable pole design that accommodates the overall portable pole goal while being in operation mode. It is, however, desirable to keep the weight 
down during transportation. To reach this, we propose creating the pole as a hybrid between a type- 2 and type- 4 , meaning that the pole is compact and has a reduced weight during transportation, but which in operation mode remains robust and stable. One of the main weight contributors in the DLR setup is the concrete base which the entire pole is installed on. Naturally, a proper frame is needed to keep the base stable; however, all additional weight needed should be configurable. In Figure 12 the proposed base design of the portable pole is seen. The entire square platform consists of a steel frame containing 4 slots for mounting standard tiles in a vertical rack. The tiles can be acquired in most construction and hardware stores around the world, i.e. $30 \times 60 \times 6 \mathrm{~cm}$ tiles with a weight of $25 \mathrm{~kg}$ each. Depending of the required base weight, one of the tiles slot could be used for the equipment cabinet rather than placing it next to the base. Finally, the base platform has 4 adjustable feet for leveling its height on site in case the pavement is not well levelled.

The swivel bracket installed in the middle of the base platform will be used for raising the lattice mast as seen in Figure 13. The deployment of the portable pole is done by installing tiles in 3 of tiles slots on the base platform leaving 1 slot open. The lattice mast is connected to the swivel bracket in the center of the base platform and put horizontally on the ground in the open tiles slot direction. Our portable pole consists of 5 lattice mast sections, which are 2 meters each providing a 10 meters long lattice mast. The lattice mast and base can be completely separated to ease transportation.

To raise the assembled lattice mast, a steel wire is attached to the mast and directed towards a temporary installed vertical steel mast on the base platform. On this temporary installed steel mast, a manual winch system is installed, which by the use of hand-power can lift the lattice mast to its operational position where it is locked. Afterwards the temporary equipment is removed and the last tiles slot is equipped with tiles finalized the deployment of the portable pole. When deployed, 11 tiles are installed in each slot, providing a total weight of $1100 \mathrm{~kg}$ in the base framework.

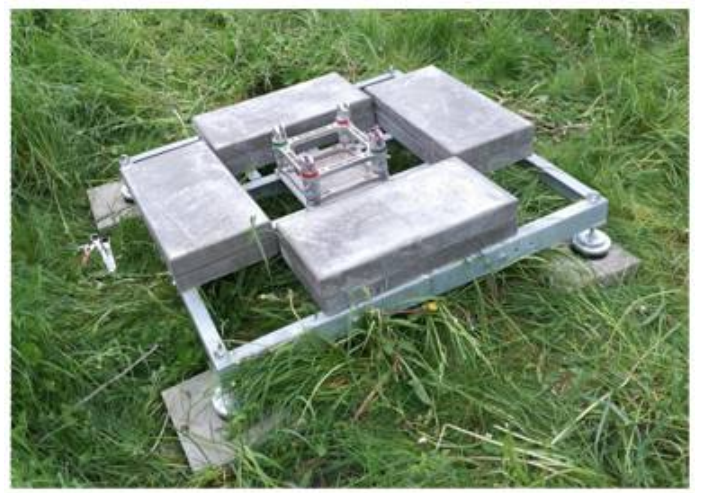

Figure 12. The ground base of the portable pole is equipped with tiles, adjustable feet, and a swivel bracket to ease the raising of the lattice mast. 

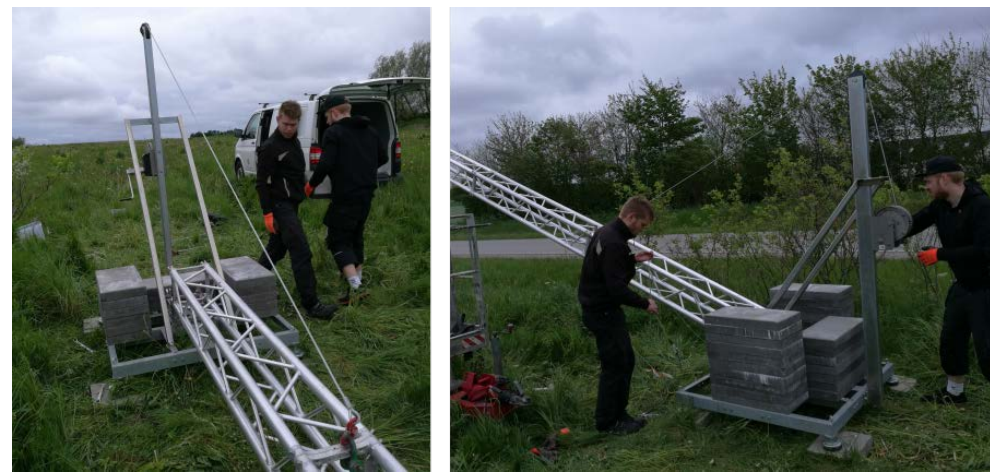

Figure 13. The portable pole can be raised using a swivel bracket installed in the middle of the base platform. The pole is raised using a steel wire connected to a manual winch system.

The cameras used to derive the payload for this proposal are defined in the requirements seen in Table 1. In addition to those cameras, we propose to include the Axis YP3040 Pan-Tilt Motor, as remote camera control has been found desirable for the setup. This, however, increases the minimum required payload weight for the portable pole with $4.2 \mathrm{~kg}$.

The Axis YP3040 has a maximum load of $8 \mathrm{~kg}$ meaning that a custom mounting rig needs to be created to hold both cameras whilst being mounted. The custom mounting rig is seen in Figure 14. The overall weight of the camera setup, including a buffer, is therefore estimated to be $12 \mathrm{~kg}$.

The final proposal of the TRG-pole in operation mode can be seen in Figure 15 , where you could install your equipment on, e.g. the custom mounting rig. The deployment of the portable pole is 2 hours for 2 persons and requires a van and a trailer. A visual introduction and description of the portable pole can be seen at https://www.youtube.com/watch?v=SjZlWb3hmBo. In Table 10 the specifications of the TRG-pole are summarized.

\section{Traffic Analysis Using TRG-Pole}

The TRG-pole can be deployed in rural areas, which can be of particular use as there in some scenarios are no to limited existing infrastructure (light poles, balconies, trees, etc.) to mount the camera equipment in. For instance, it has been used for a traffic safety analysis as seen in Figure 16, where there were otherwise limited options besides deploying the TRG-pole.

But what really makes the TRG-pole a great tool, is that the very compact base framework allows it to be deployed in most urban areas as well. Though there might exists multiple options in most urban areas, it is however not guaranteed that it provides an ideal capturing angle for the camera equipment. A limited or bad camera view-angle will impact the overall quality of the traffic analysis. An example of this is shown in Figure 17, where a traffic intersection in Aalborg is used for a traffic analysis study. The left red circle marks a camera mounted in the existing infrastructure, i.e. lighting pole, and the right red circle marks the 

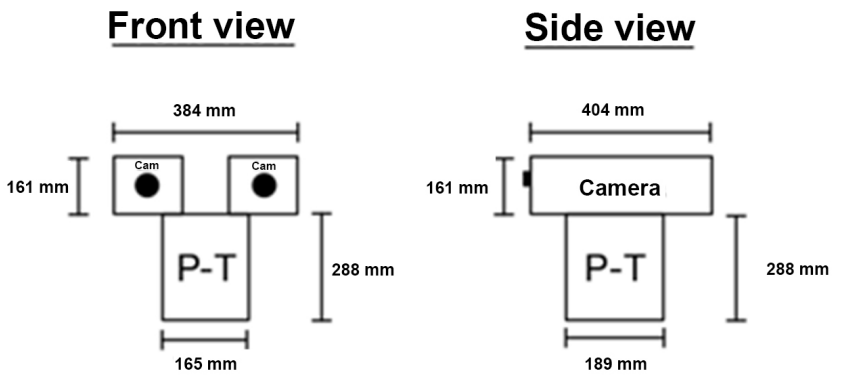

\section{Front-Side view}

Figure 14. The portable pole can be equipped with a camera rig containing two cameras, e.g. RGB and thermal camera, and a pan-tilt motor to ease view-angle adjustments.
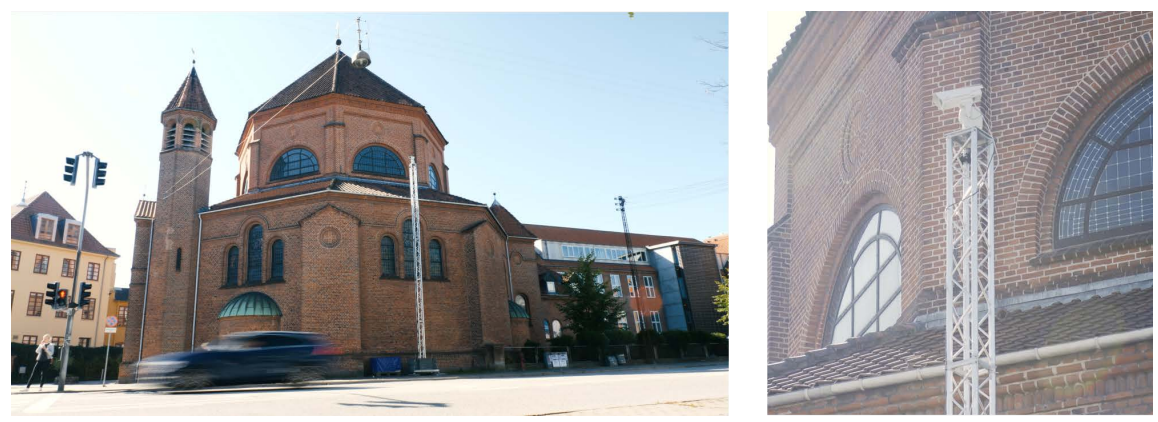

Figure 15. The portable pole deployed at traffic intersection. The pan-tilt motor with one RGB camera is installed on the top of the pole, which makes the RGB camera adjustable remotely.

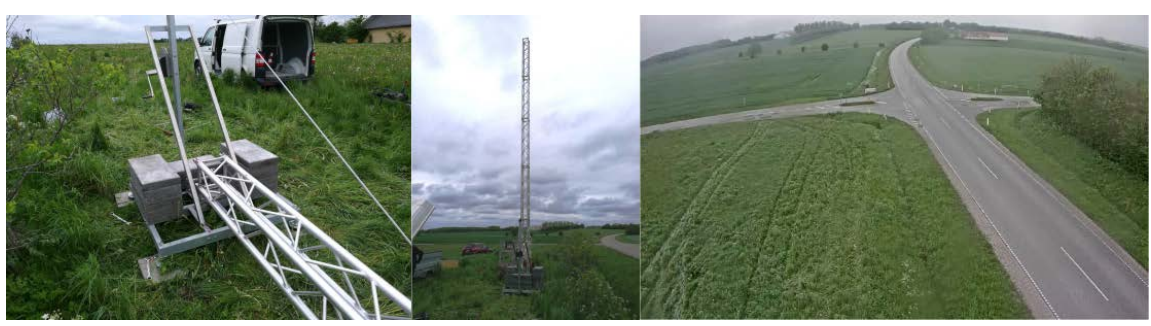

Figure 16. The TRG-pole is deployed at a traffic intersection with limited existing infrastructure.

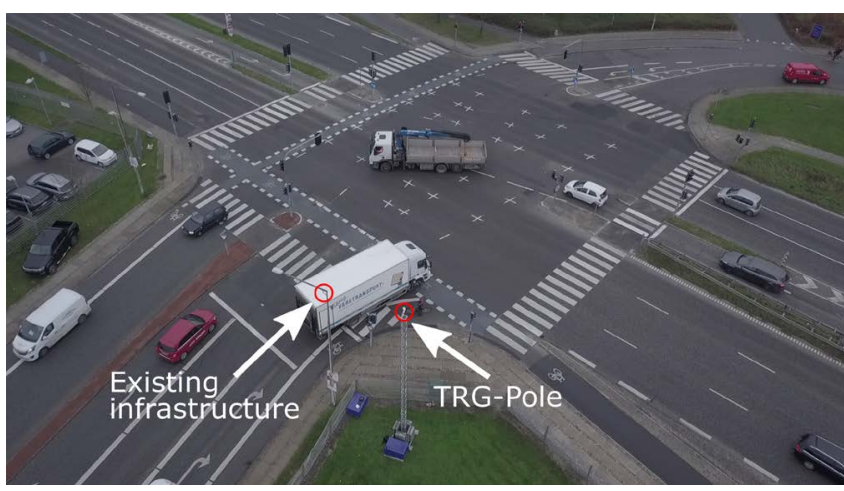

Figure 17. The existing infrastructure does not already provide ideal capturing positions for a traffic analysis. The usage of TRG-pole provides more ideal options due to its compactness. 
Table 10. Summary of techincal parameteres of the TRG-pole.

\begin{tabular}{ccccccc}
\hline $\begin{array}{c}\text { Operational } \\
\text { height }[\mathrm{m}]\end{array}$ & $\begin{array}{c}\text { Payload } \\
{[\mathrm{kg}]}\end{array}$ & $\begin{array}{c}\text { Operational base dimensions } \\
{[\mathrm{L} \times \mathrm{W} \times \mathrm{H}[\mathrm{m}]]}\end{array}$ & $\begin{array}{c}\text { Transport dimensions } \\
{[\mathrm{L} \times \mathrm{W} \times \mathrm{H}[\mathrm{m}]]}\end{array}$ & $\begin{array}{c}\text { Operational } \\
\text { weight }[\mathrm{Kg}]\end{array}$ & $\begin{array}{c}\text { Configurable } \\
\text { Deployment equipment }\end{array}$ \\
\hline 10 & 12 & $1.2 \times 1.2 \times 10$ & - & 1239 & Yes & Van, trailer \\
\hline
\end{tabular}

camera installed in the TRG-pole. The corresponding output camera feeds are seen in Figure 18, where the existing infrastructure clearly captures the same objects as the TRG-pole does. The camera installed in the existing infrastructure do however not capture the entire cycling box and the camera's view of field do only allow a limited area of the cycling road after the cyclists begin turning right. Though the TRG-pole is deployed only a few meters away from the lighting pole, the TRG-pole provides a better capturing view for examining the potential conflicts between a cyclist and a right-turning vehicle.

Using semi-automated image processing tools, e.g. RUBA [18], you can use the TRG-pole to conduct traffic analysis with a large variety of scopes, e.g. traffic counts, speed estimations, conflicts, etc. The 10 meters high pole makes a great platform for doing traffic counts as video from such a height is less occlusion prone compared to most existing infrastructure. An example of traffic counts done using the TRG-pole together with RUBA is seen in Figure 19, where two detectors were made to register the traffic volumes for respectively one of the entrances to the intersection (A) and one of the left-turning streams from the main road to the side road $(B)$.

\section{Discussion}

The presented portable poles types and corresponding solution have been heavily compared and discussed in Section 3.6 in a structured manner given a set of minimum requirements. The requirements have been heuristically derived and the essential requirements defined are thus biased. The remarks made for each of the surveyed solutions is therefore application depended and might still serve beneficial for other application. Most of the type-1 solution, e.g. the Miovision Scout, might be ideal to make a preliminary study at a point of interest prior to deploying a larger solution. To ensure that the final traffic analysis of the point of interest remains of high quality, the captured data must be of equally good and stable quality. A larger solution is thus necessary to ensure this during longer capturing periods due to various real-life challenges, e.g. weather, vandalism, etc.

The proposed portable pole design is not as easy deployable as most of the type- 1 solutions and type- 2 solutions, but do not require any guying system for maintaining and ensuring stability. In this proposal it is at most needed as a safety precaution during deployment. The main drawback of the type- 4 solution is the transportation weight, which in this hybrid version of type-2 solutions and type-4 solution is reduced while remaining stable during operation. Even though the transportation weight is reduced significantly by removing the tiles from the 


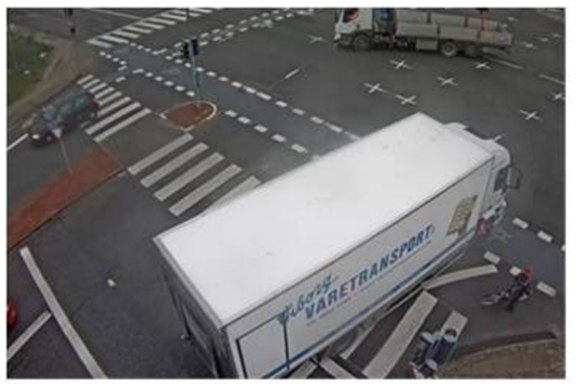

(a)

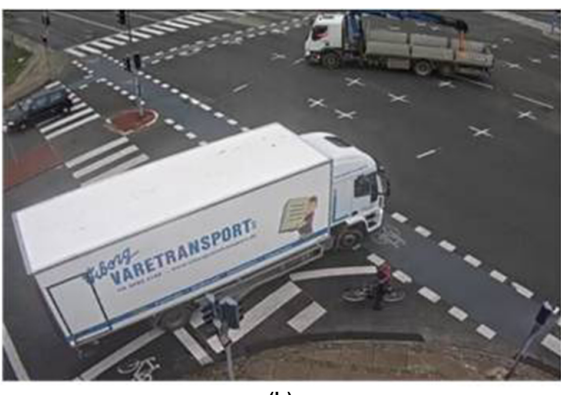

(b)

Figure 18. Video feed from the camera installed in (a) the existing infrastructure (b) the TRG-pole.

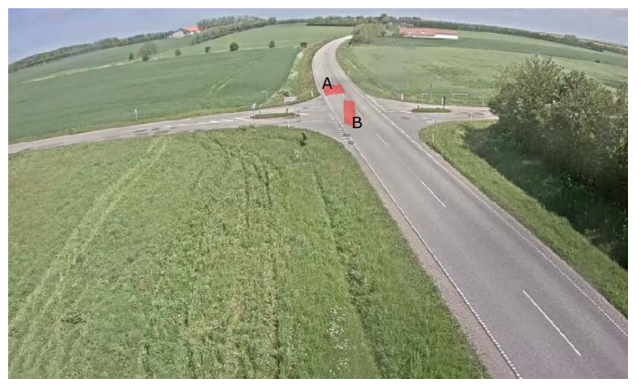

Figure 19. Two movement detectors registered the traffic flows through the detectors.

portable pole base, the frame remains large and made out of steel, meaning that 2 persons and some deployment equipment are still required. An additional drawback of the type- 4 solution, and possibly portable poles in general, is the fact they might ruin the naturalistic environment for the drivers, and therefore ruin the desired naturalistic data. The portable pole proposed in this paper do still struggle with this issue, as a portable pole looking similar to the illustration seen in Figure 15 might still be considered obtrusive in a traffic intersection. But compared to most of the other solution, it is however considered less obtrusive.

The proposed portable pole does to some extent get inspiration and some ideas from the Trivector mobile mast, UTRaCAR, and the DLR platform solutions. These are however all considered to be quite expensive solutions, especially the Trivector mobile mast and UTRaCAR is considered expensive due to the large acquiring and remodeling price of a trailer and a car, respectively. The proposed portable pole is considered a lot cheaper to manufacture due to its simple structure and base framework.

\section{Conclusions}

This paper presents a survey, proposal, and analysis of portable poles in relation to capturing data in traffic intersection. The surveyed portable pole solutions were split into 4 general types. The type- 4 solution appears to fit the defined minimum requirements most, however with a major shortcoming as it is also the lesser mobile and portable pole solution. This leads to the conclusion that for 
capturing the most stable and useful data, the setup must comprise the lightweight and easy mobility requirements. For the type- 1 and type- 2 solutions to work, various guying system must be installed on existing infrastructure to fixate the pole. If one involves the existing infrastructure, a better result would be reached if the capturing rig is mounted on the infrastructure rather than using a lightweight or compact portable pole with guying installation. The DLR solution in type- 4 is considered to be the best portable pole solution based on vandalism prevention, robustness, stability, and still somehow transportable.

The DLR solution does however not completely fulfill the overall portable pole goal defined in this journal due to the limited mobility. We therefore propose a new portable pole design which combines elements from the type- 2 solutions and the type- 4 solution so that the overall portable pole goal is reached. The proposed portable pole will get the mobility from the type- 2 solutions and get the robustness and stability from the type- 4 solution. The proposed design is inspired by the type- 4 solution from DLR as we also propose to split usage of the portable pole into a transportation stage and an operation stage. The weight of the entire setup can dynamically and with ease be adjusted allowing a more lightweight solution and easier transportation stage. The weight during operation is, however, still intact, such the stability is kept. The proposed portable pole can be deployed by 2 persons in 2 hours in both rural areas as well as urban areas due to its compactness.

\section{Acknowledgements}

The authors would like to thank Kay Gimm and Sascha Knake-Langhorst from Deutsches Zentrum für Luft- und Raumfahrt (DLR) for the aid in information about the Test field AIM (Application Platform for Intelligent Mobility) and the UTRaCar. This project has received funding from the European Union's Horizon 2020 research and innovation programme under grant agreement No 635895. This publication reflects only the authors' view. The European Commission is not responsible for any use that may be made of the information it contains.

\section{Conflicts of Interest}

The authors declare no conflicts of interest regarding the publication of this paper.

\section{References}

[1] European Commission (2018) 2017 Road Safety Statistics: What Is behind the Figures? http://europa.eu/rapid/press-release_MEMO-18-2762_en.pdf

[2] European Commission (2010) Towards a European Road Safety Area: Policy Orientations on Road Safety 2011-2020. European Commission. https://ec.europa.eu/transport/sites/transport/files/road_safety/pdf/com_20072010_ en.pdf

[3] Neale, V.L., Dingus, T.A., Klauer, S.G., Sudweeks, J.D. and Goodman, M.J. (2005) 
An Overview of the 100-Car Naturalistic Study and Findings.

[4] Davis, G. and Hourdos, J. (2012) Development of Analysis Methods Using Recent Data: SHRP 2 Report. Transportation Research Board.

[5] Philipsen, M.P., Jensen, M.B., R. Satzoda, K., Trivedi, M.M., Moeslund, T.B. and Møgelmose, A. (2015) Day and Night-Time Drive Analysis Using Stereo Vision for Naturalistic Driving Studies. IEEE Intelligent Vehicles Symposium, Seoul, 28 June-1 July 2015, 1226-1231. https://doi.org/10.1109/IVS.2015.7225850

[6] Hydén, C. (1987) The Development of a Method for Traffic Safety Evaluation: The Swedish Traffic Conflicts Technique. No. 70, Bulletin Lund Institute of Technology.

[7] Fyhri, A., Sundfør, H., Bjørnskau, T. and Laureshyn, A. (2017) Safety in Numbers for Cyclists-Conclusions from a Multidisciplinary Study of Seasonal Change in Interplay and Conflicts. Accident Analysis \& Prevention, 105, 124-133.

[8] Madsen, T.K.O. and Lahrmann, H. (2017) Comparison of Five Bicycle Facility Designs in Signalized Intersections Using Traffic Conflict Studies. Transportation Research Part F: Traffic Psychology and Behaviour, 46, 438-450.

[9] Sakshaug, L., Laureshyn, A., Svensson, Å. and Hydén, C. (2010) Cyclists in Roundabouts-Different Design Solutions. Accident Analysis \& Prevention, 42, 1338-1351. https://doi.org/10.1016/j.aap.2010.02.015

[10] Transport-, Bygnings- og Boligministeriet (2016) Bekendtgørelse om køretøjers største bredde, længde, højde, vægt og akseltryk (Dimensionsbekendtgørelsen). https://www.retsinformation.dk/pdfPrint.aspx?id=137554

[11] I.T. Forum (2015) Permissible Maximum Dimensions of Lorries in Europe. International Transport Forum. https://www.itf-oecd.org/sites/default/files/docs/dimensions_0.pdf

[12] Plainis, S., Murray, I.J. and Pallikaris, I.G. (2006) Road Traffic Casualties: Understanding the Night-Time Death Toll. Injury Prevention, 12, 125-138. https://doi.org/10.1136/ip.2005.011056

[13] Miovision Scout Video Collection Unit. https://miovision.com/scout/

[14] DLR UTRaCar und MoMoCar. https://www.dlr.de/ts/desktopdefault.aspx/tabid-1237/5441_read-12153

[15] Junghans, M. (2013) Situations- und Gefahrenerkennung in Verkehrsszenen. Kolloquium Verkehrsmanagement und Verkehrstelematik.

[16] Clark Masts Model 804/15-6 Heavy Duty Trailer Mast. Clark Masts. http://www.clarkmasts.com/products/trailers/804-series-trailer-masts/

[17] Sascha, K.-L. and Gimm, K. (2016) AIM Mobile Traffic Acquisition: Instrument Toolbox for Detection and Assessment of Traffic Behavior. Journal of Large-Scale Research Facilities, 2, A74.

[18] Bahnsen, C., Madsen, T.K.O., Jensen, M.B., Lahrmann, H.S. and Moeslund, T.B. (2018) RUBA-Road User Behaviour Analysis. Aalborg.

[19] Clark Masts FT Series, Clark Masts, 9 May 2012. http://www.clarkmasts.com/media/dyn-docs/products/ft-masts-brochure.pdf

[20] Clark Masts QT Series. Clark Masts. http://www.clarkmasts.com/media/dyn-docs/products/qt-range-mk6-uk-details.pdf

[21] Flyintower 7.5-500 \& 9.5-600. Litec Strutture \& Soluzioni. https://www.litectruss.com/getmedia/3162a9f9-70ca-422c-b6af-f863f62cf6f2/Flyinto wer-7,5-500-9-5-600_catalogue.pdf.aspx?ext=.pdf 